\title{
Analysis of Factors Influencing the Long-term Outcome in Primary Spinal Cord Tumors: Review of Literature
}

\author{
Uddanapalli Sreeramulu Srinivasan ${ }^{1, \odot ~ N a t a r a j a n ~ R a g h u n a t h a n ² ~}$ \\ ${ }^{1}$ Department of Neurosurgery, Sri Balaji Hospital, Guindy, Chennai, \\ Address for correspondence Uddanapalli Sreeramulu Srinivasan, \\ Tamil Nadu, India \\ ${ }^{2}$ Department of Neurosurgery, MIOT Hospitals, Manapakkam, \\ Chennai, Tamil Nadu, India \\ MCh, IFAANS, 3A Malavika Apartments, New No 70 3rd Main Road, \\ Gandhinagar, Adyar, Chennai 600020, Tamil Nadu, India \\ (e-mail: drussrinivasan@gmail.com, sadhanasmruthi@gmail.com).
}

Indian J Neurosurg 2022;11:118-122

\begin{abstract}
Introduction Primary spinal cord tumors are amenable to total surgical excision but the outcomes are still diverse.

Objective The purpose of this study is to identify the significant factors which influence the long-term outcome of spinal cord tumors.

Materials and Methods A total of 84 consecutive spinal cord tumor patients who underwent microsurgical excision during April 2003 to 2014 were retrospectively studied. Patients operated after April 2014 were not considered. Ten factors were taken and correlated with the outcome. Multiple regression analysis was used. Patients were periodically evaluated at 1,6 months, 1,2 , and 5 years. In 72 cases, postoperative MRI scans were performed. The follow-up period ranged between 5 to 15 years.

Results In our study, we had 64 extramedullary tumors and 21 intramedullary tumors with varied pathology. Axial location of the tumour (20.294/0.000), extent of the resection of the tumour (13.827/0.001), preoperative Nurick grade (11.349/0.023), and location of the tumour in the spine with respect to vertebral segments $(8.151 / 0.017)$ were significant predictive factors. We had good outcomes in 65 cases and poor outcomes in 19 cases.

\section{Keywords}

- spinal cord tumors

- extramedullary tumor

- intramedullary tumor

Conclusion Our results show location of the tumor with respect to axial plane and vertebral segments were the main contributing factors. They influence the extent of excision of the spinal cord tumor. Preoperative neurological status is the fourth factor which independently determines the long-term outcome. It is one of the few papers where patients have been followed-up for a long period ranging from 5 to 15 years.
\end{abstract}

\section{Introduction}

Spinal cord tumors account for 5 to $10 \%$ of all primary central nervous system (CNS) tumors. Approximately $25 \%$ are extramedullary, and primary intramedullary tumors comprise 10 to $15 \%{ }^{1,2}$ Of extramedullary tumors, neurofibroma
(25\%) and meningioma (20\%) are the most common..$^{1,2}$ Spinal ependymoma constitutes the majority of intramedullary spinal cord tumors. Although the majority of spinal tumors are amenable to total surgical excision, the factors determining the outcome are diverse. published online

November 24, 2021
DOI https://doi.org/

10.1055/s-0041-1726609

ISSN 2277-954X
(C2021. Neurological Surgeons' Society of India.

This is an open access article published by Thieme under the terms of the Creative Commons Attribution-NonDerivative-NonCommercial-License, permitting copying and reproduction so long as the original work is given appropriate credit. Contents may not be used for commercial purposes, or adapted, remixed, transformed or built upon. (https://creativecommons.org/licenses/by-nc-nd/4.0/).

Thieme Medical and Scientific Publishers Pvt. Ltd. A-12, 2nd Floor, Sector 2, Noida-201301 UP, India 


\section{Aim}

To analyze the factors influencing the neurological long-term outcome during and after the microsurgical excision of primary spinal cord tumors.

\section{Materials and Methods}

A retrospective study of 84 patients who underwent microsurgical excision of primary spinal tumors during the period April 2003 to April 2014 was done. Patients operated after April 2014 were not considered, since they had not completed the five-year follow-up period. All patients had preoperative MRI scan of the spine with contrast. Following surgical excision of the spinal cord tumors, histopathological confirmation was carried out in all cases.

Only primary extramedullary and intramedullary tumors only were included in this study. The exclusion criteria were primary and secondary bony spine tumors. The follow-up period ranged between 5 and 15 years. All these patients were periodically followed-up at the end of 1, 6, 12 months, and 2 years. At the end of 5 years, these patients were reexamined by communicating to them through various modes and requesting them to come for follow-up. Follow-up MRI scan with contrast of the involved region with screening of the entire spine was performed in 72 cases.

The following 10 factors were analyzed for any significant correlation with the outcome in these patients: (1) age, (2) sex, (3) duration of symptoms, (4) preoperative Nurick grade, $^{3}(5)$ size of the tumor with relationship to vertebral body, (6) axial location, (7) location in the spine, (8) associated MRI findings, (9) extent of resection, (10) histopathology of the tumor.

Of the 84 primary spinal cord tumors, 61 were extramedullary and 23 were intramedullary tumors. Age range was between 5 to 73 years. There were 33 males and 51 female patients. Duration of symptoms was classified into three groups: $\leq 6$ months, $6 \mathrm{~m}-1$ year, $>1$ year. Nurick's grade ${ }^{3}$ on admission was applied to all spine cases as a protocol, which was evaluated and documented ( $\boldsymbol{- T a b l e} \mathbf{1}$ ). The size of the lesion with respect to the vertebral body levels were graded as a) Spanning 1 (vertebral body) to 2 vertebral bodies; b) 3 to 4 vertebral bodies; c) 5 and more vertebral bodies. The axial location of the tumor was classified as 1 ) anterior (19 cases); 2) anterolateral (8 cases); 3 ) posterior (12 cases);

Table 1 Preoperative Nurick grade in 84 patients

\begin{tabular}{|l|l|}
\hline Nurick's grade & $\begin{array}{l}\text { No. of } \\
\text { cases }\end{array}$ \\
\hline 0: No root signs or cord signs & 0 \\
\hline 1: Cord pathology-gait intact & 32 \\
\hline 2: Mild gait dysfunction-employed & 13 \\
\hline 3: Gait dysfunction-unemployed & 13 \\
\hline $\begin{array}{l}\text { 4: Moderate to marked gait dysfunction but } \\
\text { ambulates with help }\end{array}$ & 11 \\
\hline 5: Marked gait disturbance/wheelchair & 15 \\
\hline
\end{tabular}

4) posterolateral (45 cases) ( - Fig. 1). Location in the spine was taken into consideration and divided as 1) cervical (12 cases) 2] dorsal (42 cases); 3) lumbosacral (30 cases). Associated MRI findings were analyzed under the following categories: 1) multiple lesions, 2) syrinx, and 3) hyperintense signal within the spinal cord. Extent of resection of the tumor was analyzed as incomplete resection, which could be either of the following: 1) partial resection-macroscopically majority of the tumor left in situ; 2) radical resection, with part of the tumor left in situ, as noted under microscope, but macroscopically negligible. We had extramedullary dumbbell neurofibroma in 15 cases where the extraspinal part was left in situ in the first stage, and it was categorized as partial resection. Eleven cases of intramedullary tumors which fell in the category of radical resection; 3) complete resection as seen under microscope (58 cases). Histopathology of the spinal cord tumors as per internationally accepted classification was used and reported by the pathologist. All the above 10 factors were correlated with the outcome.

\section{Results}

Statistical analysis was performed using Statistical Package for the Social Sciences (SPSS). Multiple regression analysis was used. Pearson Chi-square test was chosen to identify the significant variables among the 10 variables studied. We have defined in this paper good and poor outcome following surgical intervention of the spinal cord tumors. Good outcome was defined as those who improved after surgical intervention or whose neurological status remained in Nurick grade 1 to 2 or no tumor recurrence on follow-up. Poor outcome was defined as those who deteriorated neurologically or remained in Nurick's grade 3 to 5 or had recurrence of the tumor which required surgery.

Results of statistical analysis of the 10 variables, taken into calculating the likely outcome, showed axial location of the tumor $(20.294 / 0.000)$, extent of the resection of the tumor (13.827/0.001), preoperative Nurick grade (11.349/0.023), and location of the tumor in the spine $(8.151 / 0.017)$ were significant predictive factors among the 10 variables. These variables correlated with the outcomes which we had defined ( - Table 2) above in this article.

\section{Discussion}

Maurya et $\mathrm{al}^{4}$ in their analysis of 32 cases of $\mathrm{C} 1-\mathrm{C} 2$ nerve sheath tumor was classified, based upon the axial location of the tumor as anterior, anterolateral, posterolateral, and posterior. They were able to achieve partial resection in two cases, out of which one is anteriorly placed tumor and another was a dumbbell tumor, forming a subtotal of 4 cases among 32 cases. They concluded that operative results and recovery of patients are excellent when the tumor is located posterior or posterolaterally and surgical procedure is done early in the disease process.

Tanmoy et $\mathrm{al}^{5}$ in their series of 38 cases of spinal meningiomas had two cases which were located ventrally, and in those cases, they did not attempt dural resection. They also 
1. Anterior: 19 cases

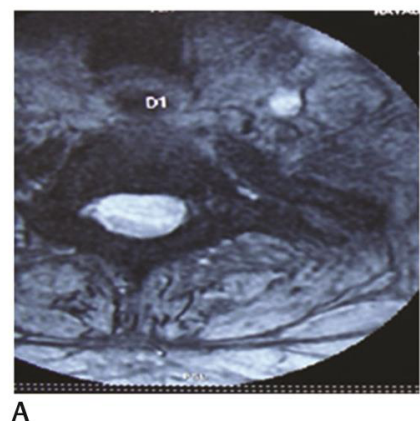

3. Posterior: 12 cases

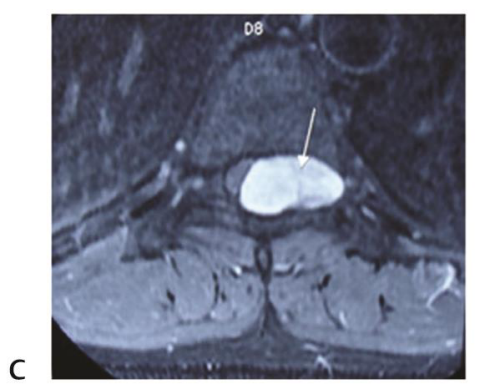

\section{Antero-lateral: 8 cases}

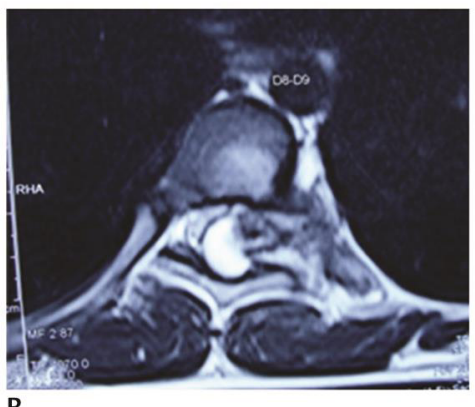

4. Postero-lateral: 45 cases

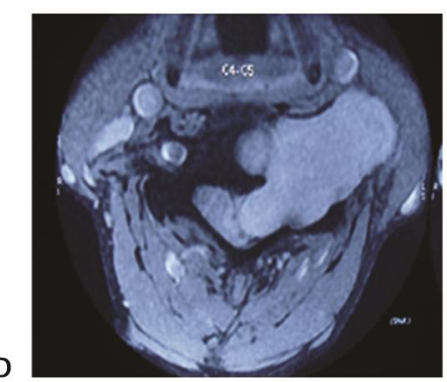

Fig. 1 Axial location of the spinal cord tumor as observed in MRI scans. (A) Anterior; (B) Anterolateral; (C) Posterior and; (D) Posterolateral.

state that dorsal or dorsolateral lesions are easier to resect when compared to ventral or ventrolateral meningiomas. Their results revealed that ventral or ventrolateral location of spinal meningiomas were associated with poor functional outcome at 1-year follow-up, in addition to other significant parameters like presence of T2 hyperintense signal, large tumor size, and poor preoperative neurological status.

Mehta et $\mathrm{al}^{6}$ in their analysis of 96 patients with intradural extramedullary tumors observed that anteriorly located tumors in the upper thoracic spine were found to have the highest rate of surgery-related complications and postoperative neurological deficits. Among 12 cases which were located anteriorly, 41.6\% developed surgery-related complications, whereas for all lateral tumors $(n=69)$, it was $4.4 \%$ only, and that for all posteriorly located tumors $(n=17$ ) was $0 \%$. Jacob ${ }^{7}$ had transient motor deficits in two anteriorly placed tumors in thoracic the region operated via a posterior approach.

Singh et $\mathrm{al}^{8}$ in their 44 cases categorized the axial location of the tumor as anterior, posterior, or lateral with respect to the spinal cord, which were described to correlate with a clock face. The tumors that were predominately between "10 and 2 o' clock " were considered anterior, while if tumor predominately occupied " 4 to 8 o' clock," then they were considered posterior, and those that were either " 2 to 4 o' clock" or "8 to 10 o' clock" were considered "lateral." Based upon the axial location of tumor, they had $6.82 \%$ cases located in the dorsal/posterior region, $13.64 \%$ were located in the ventral/anterior part, while the most common axial location of tumor was lateral (79.55\%). They had deterioration in two ventrally located tumors. In tumors located in the thoracic level due to higher cord-to-canal ratio, they concluded that surgeon should always be more cautious, and purely ventral and thoracic tumor has higher chances of postop complication.

Review of literature showed only a few papers ${ }^{4-6,8}$ had analyzed the outcome based upon the axial location of the tumor within the spinal canal. In similar lines, we analyzed our data, based upon the axial location of the spinal cord tumor as anterior, anterolateral, posterior and posterolateral ( - Fig. 1). Our results showed that axial location of the spinal cord tumor is one of the most significant factors in determining the long-term outcome. In-depth analysis of this factor of axial location shows that those tumors located in the posterior or posterolateral to spinal cord were easily amenable to total excision, as stated by other authors. ${ }^{4,6,8}$ Tumors located anterior to spinal cord, even extramedullary tumors, especially in the cervical and dorsal regions, could not be excised completely in view of their location. In these cases, spinal cord could not be retracted, and approach became extremely difficult, which limited the possibility of total excision, even though histologically it was benign tumor-like meningioma and size was not also extensive like intramedullary tumors ( - Fig. 1). In the anterolateral group of tumors, the completeness of excision depended upon the extent of the tumor location more laterally within the spinal canal compared to their anterior component. Thus, subgrading of the axial location of the spinal cord tumors within the spinal canal is one of the main factors in predicting the outcome and should be taken into consideration while planning surgery and prognosticating the long-term outcome in these cases.

Chandy et $\mathrm{al}^{9}$ and Kaner et $\mathrm{al}^{10}$ concluded that gross total resection and good neurological condition before surgery as 
the most important factors in outcome in intramedullary tumors. Chamberlain et $\mathrm{al}^{1}$ concluded that the predictors of outcome include preoperative neurological status (limited to no neurological deficit, predicts for improved survival), extent of surgical resection (image verified complete resection, improves survival), and histological grade (lower grade, predicts for improved survival). Similar conclusions were reached by Aghayev. ${ }^{11}$ Hufuna et al ${ }^{12}$ reported that duration of symptoms and completeness of excision were important factors, but not the axial location of the tumor and spinal level affected. Our results also suggest that preoperative neurological status and completeness of excision are the next most important factors in determining the long-term outcome.

In our study out of 10 factors we analyzed, we found the following four factors significantly correlated with the outcome: location of the tumor in the axial plane, extent of the surgical resection, preoperative Nurick grade, and location of the tumor in the spine (cervical/dorsal/lumbosacral). Similar analysis was performed by Jenkinson et $\mathrm{al}^{13}$ in which the following factors analyzed were identical to our study ( - Table 2 ). They are age, duration of symptoms, complete resection of the tumor, tumor histology, and pre and postop Frankel grade (we used Nurick grading system). In addition to the above, they analyzed the use of adjuvant therapy and recurrent tumor. They analyzed the outcome separately for extramedullary and intramedullary spinal cord tumors. In their analysis, they stated that in extramedullary tumors, statistical analysis did not show any significant contributory variables. In intramedullary tumors, a better postoperative Frankel grade favored survival, whereas recurrence and use of adjuvant therapy did not favor survival. Their study also points out that irrespective of histological diagnosis, preoperative functional status is the best predictor of functional outcome for both types of spinal cord tumors. Our results are agreeable with the above statement that preoperative functional status is one of the best predictors of functional outcome.

Jenkinson et $\mathrm{al}^{13}$ states in cases of recurrent astrocytoma and ependymoma further surgery is unlikely to benefit, where macroscopic excision of the tumor was not possible at the initial operation. Adjuvant therapy given in such cases with chemotherapy was not useful. Here we differ from them, since we had a case of intramedullary dermoid cyst in a child with good preoperative neurological status, in whom we had operated thrice over a span of 12 years with good postoperative functional outcome. The child is walking independently after the third surgery. A similar case we had in another child with intramedullary astrocytoma where there was recurrence; reoperation was carried out and the child was walking independently even after the second surgery. Hence, we suggest, even partial debulking of the intramedullary tumors in case of recurrence, especially in those with good preoperative functional status, has good long-term functional outcome. Further analysis of Jenkinson's et $\mathrm{al}^{10}$ study shows they had recurrences in five cases of benign tumors like meningioma and schwannoma whom they reoperated without deterioration in functional outcome. This supports our view that reoperation in patients with good preoperative functional status is beneficial to the patient.
Yamane et $\mathrm{al},{ }^{14}$ who analyzed various factors predicting clinical impairment after surgery for cervical spinal schwannoma, observed that dumbbell tumors had high incidence of tumor recurrence, especially those involving C5-C8 nerve roots where excision of the ventral nerve root was not possible. In their series of 18 patients with dumbbell tumors, only 4 out of 18 patients had total removal. In our series, we had 7 dumbbell tumors, out of which 4 were located in the cervical and 3 in the dorsal region. In the dorsal region, initially the spinal part of the tumor was excised by the neurosurgical team, followed by excision of the intrathoracic component by the cardiothoracic team. There were no recurrences in these cases. In the cervical region, we had two upper cervical C2C3 tumors where only the intraspinal component was excised up to the exit into the foramen. Follow-up of these patients with MRI scan for more than 6 years did not reveal recurrences within the spinal canal. The extraspinal part located at C2-C3 level was asymptomatic. The two other cases were at C7-T1 level, where they had wasting of the muscles supplied by the respective nerve roots and hence were totally excised in two stages. There was no recurrence even in these cases on long-term follow-up.

Stawicki et al ${ }^{15}$ reported four recurrences in their 67 cases, among which two were dumbbell schwannomas, one schwannoma, and one ependymoma, which were partially excised in the first stage. Chang et $a{ }^{16}$ state that the extent of excision to be statistically significant in determining disease recurrence in ependymoma. These results confirm that the extent of surgical resection influences the final outcome in spinal cord tumors.

On critical analysis, we noted that most of the articles discuss the size of spinal cord tumors in centimeters, but practically in some of our referred cases with MRI scans performed outside our center, size was not measured. In the series reported by Hufuna, ${ }^{12} 23$ out of 93 patient's tumor size were not recorded and that accounts for nearly $25 \%$ of their cases. Repeating the MRI scan again for measuring the size of the tumor was not cost-effective. We propose a practical scale regarding the length of the tumor, which needs to be defined with relationship to the vertebral body segments rather than quantified exactly in terms of unit of length in the metric system.

On analyzing the influence of associated lesions observed in MRI in predicting the outcome, we like to state that we had a case of von Recklinghausen's disease who presented with quadriplegia with Nurick grade 4. Once the offending cervical neurofibroma was excised, the patient improved neurologically by more than 3 grades from Nurick grade 4 to grade 1 and is asymptomatic for the past 10 years. This case justifies that multiple lesions does not influence the outcome. Tanmoy et $\mathrm{al}^{5}$ reported that T2 cord signal changes noted in the MRI were associated with poor functional outcome. Our results differ in this regard with them, since they had analyzed only a subset of spinal tumors meningiomas, while we considered all types of spinal intradural tumors. This would have led to a statistical bias, which would have influenced the final variables predicting the poor functional outcome. 
Table 2 Results of statistical analysis of 10 factors in 84 patients

\begin{tabular}{|l|l|l|l|}
\hline S. No & Factors analyzed & Pearson Chi-square test values & Statistical significance \\
\hline 1 & Age & 2.041 & 0.360 \\
\hline 2 & Sex & 2.246 & 0.134 \\
\hline 3 & Duration of symptoms & 6.038 & 0.049 \\
\hline 4 & Preop Nurick grade & $11.349^{\text {a }}$ & 0.023 \\
\hline 5 & Size of the tumor with relationship to Vertebral body & 3.306 & 0.191 \\
\hline 6 & Axial location & $20.294^{\text {a }}$ & 0.000 \\
\hline 7 & Location in the spine & $8.151^{\text {a }}$ & 0.017 \\
\hline 8 & Associated MRI findings & 1.312 & 0.252 \\
\hline 9 & Extent of resection & $13.827^{\text {a }}$ & 0.001 \\
\hline 10 & Histopathology & 0.871 & 0.647 \\
\hline
\end{tabular}

aStatistically significant factors.

We like to conclude that multiple factors play a role in determining the functional outcome, as varying results were reported in different studies. . $4,6,8,10,12-15$ Our study highlights and reemphasizes the importance of location of the tumor in the axial plane to be taken into consideration while planning the surgery and prognosticating the long-term outcome. Except in very few studies, this factor is not given importance in prognosticating the outcome. Majority of the published studies are in agreement that the extent of excision of the spinal cord tumor and preoperative neurological status in spinal cord tumor patients influences the long-term final outcome. Our results are also in agreement with them. Location of the tumor in the spine (cervical/dorsal/lumbosacral) were other main contributing factors in predicting the neurological outcome in patients with primary spinal tumors. At the earliest evidence of recurrence of the tumor when the patient has good neurological status, they have to be reoperated to obtain good long-term functional outcome, which was done in four of our patients. It is one of the longest follow-ups where the patients who have been operated for spinal cord tumors have been followed-up for a period ranging between 5 to 15 years.

\section{Conflict of Interest}

None declared.

\section{Acknowledgement}

The authors wish to acknowledge the support given by Prof. Dr. P. V.A. Mohandas, Managing Director of MIOT hospitals, Chennai, Tamil Nadu, India, and Dr. L. S. Subramaniam, Managing Director of Sri Balaji Hospitals, Chennai, Tamil Nadu, India.

\section{References}

1 Chamberlain MC, Tredway TL. Adult primary intradural spinal cord tumors: a review. Curr Neurol Neurosci Rep 2011; 11(3):320-328

2 Traul DE, Shaffrey ME, Schiff D. Part I: spinal-cord neoplasmsintradural neoplasms. Lancet. Oncology.thelancet.com 2007; $8(1): 35-45$
3 Nurick S. The pathogenesis of the spinal cord disorder associated with cervical spondylosis. Brain 1972;95(1):87-100

4 Maurya P, Singh K, Sharma V. C1 and C2 nerve sheath tumors: analysis of 32 cases. Neurol India 2009;57(1):31-35

5 Tanmoy KM, Shyamal CB, Devi Prasad P, Piyush K, Bharat G, Anil N. Spinal meningiomas: clinic-radiological factors predicting the recurrence and functional outcome. Neurosurg Focus 2016;41(E6) :1-10

6 Mehta AI, Adogwa O, Karikari IO, et al. Anatomical location dictating major surgical complications for intradural extramedullary spinal tumors: a 10-year single-institutional experience. J Neurosurg Spine 2013;19(6):701-707

7 Jacob G. Spinal meningiomas. Personal experience and review of literature. Romanian Neurosurgery. 2014;21:147-161

8 Singh PR, Pandey TK, Ahmad F, Chhabra DK. A prospective observational study of clinical outcome of operated patients of intradural extramedullary spinal cord tumor in our tertiary care center. Romanian Neurosurgery 2018;32:632-640

9 Chandy MJ, Babu S. Management of intramedullary spinal cord tumors: review of 68 patients. Neurol India 1999; 47(3):224-228

10 Kaner T, Sasani M, Oktenoglu T, Solmaz B, Sarloglu AC, Ozer AF. Clinical analysis of 21 cases of spinal cord ependymoma: positive clinical results of gross total resection. J Korean Neurosurg Soc 2010;47(2):102-106

11 Aghayev K, Vrionis F, Chamberlain MC. Adult intradural primary spinal cord tumors. J Natl Compr Canc Netw 2011;9(4): 434-447

12 Hufana V, Tan JSH, Tan KK. Microsurgical treatment for spinal tumors. Singapore Med J 2005;46(2):74-77

13 Jenkinson MD, Simpson C, Nicholas RS, Miles J, Findlay GFG, Pigott TJD. Outcome predictors and complications in the management of intradural spinal tumors. Eur Spine J 2006; 15(2):203-210

14 Yamane K, Takigawa T, Tanaka M, Osaki S, Sugimoto Y, Ozaki T. Factors predicting clinical impairment after surgery for cervical spinal schwannoma. Acta Med Okayama 2013;67(6):343-349

15 Stawicki SP, Guarnaschelli JJ. Intradural extramedullary spinal cord tumors: A retrospective study of tumor types, locations, and surgical outcomes. The Internet Journal of Neurosurgery 2006;4:1-6

16 Chang UK, Choe WJ, Chung SK, Chung CK, Kim HJ. Surgical outcome and prognostic factors of spinal intramedullary ependymomas in adults. J Neurooncol 2002;57(2):133-139 